FEDERAL RESERVE BANK OF SAN FRANCISCO

WORKING PAPER SERIES

\title{
Optimal Monetary Policy Regime Switches
}

\author{
Jason Choi \\ University of Wisconsin-Madison \\ Andrew Foerster \\ Federal Reserve Bank of San Francisco
}

September 2020

Working Paper 2019-03

https://www.frbsf.org/economic-research/publications/working-papers/2019/03/

\section{Suggested citation:}

Choi, Jason, Andrew Foerster. 2020. “Optimal Monetary Policy Regime Switches,” Federal Reserve Bank of San Francisco Working Paper 2019-03.

https://doi.org/10.24148/wp2019-03

The views in this paper are solely the responsibility of the authors and should not be interpreted as reflecting the views of the Federal Reserve Bank of San Francisco or the Board of Governors of the Federal Reserve System. 


\title{
Optimal Monetary Policy Regime Switches*
}

\author{
Jason Choi ${ }^{\dagger} \quad$ Andrew Foerster ${ }^{\ddagger}$
}

September 9, 2020

\begin{abstract}
An economy that switches between high and low growth regimes creates incentives for the monetary authority to change its rule. As lower growth tends to produce lower real interest rates, the monetary authority has an incentive to increase the inflation target and increase the degree of inertia in setting rates in an attempt to keep the nominal rate away from the zero lower bound. An optimizing monetary authority therefore responds to permanently lower growth by slightly increasing both the inflation target and inertia; focusing solely on the inflation target ignores a key margin of adjustment. With repeated growth rate regime switches, an optimal monetary rule that switches at the same time internalizes both the direct effects of growth regime change and the indirect expectation effects generated by switching in policy. The switching rule improves economic outcomes relative to a constant rule. A constant rule may be preferred if the monetary authority attempts a switching rule but implements the wrong rule with high enough frequency.

Keywords: growth rate; optimal policy; regime switching; Taylor rule; inflation target; zero lower bound

JEL Codes: C63, E31, E52

${ }^{*}$ We thank Christian Matthes, Troy Davig, Lee Smith, Chris Otrok, Pierre Sarte, Andreas Hornstein, Guido Ascari, Leonardo Melosi, and Francesco Bianchi, as well as seminar participants at Fordham, the Richmond Fed, Virginia, William and Mary, and the SNDE, Midwest Macro, IAAE, CEF, System Macroeconomics, and Econometric Society European Meeting Conferences for helpful comments. The views expressed herein are solely those of the authors and do not necessarily reflect the views of the Federal Reserve Bank of San Francisco or the

†University of Wisconsin-Madison, Department of Economics, 1180 Observatory Drive, Madison, WI 53706,

${ }^{\ddagger}$ Federal Reserve Bank of San Francisco, 101 Market St, San Francisco, CA 94105, andrew.foerster@sf.frb.org.
\end{abstract} Federal Reserve System. jason.choi@wisc.edu. 


\section{Introduction}

The slow growth after the financial crisis and recession of 2008-2009 prompted a renewed debate about objectives and conduct of monetary policy due to structural changes that have taken place. In particular, slower growth contributed to lowering the real interest rate, leading to questions about how, if at all, the systematic conduct of monetary policy should respond to this shift. Much of the debate has called for a reassessment of inflation targets in light of a lower real interest rate.

The emphasis on changing fundamental policy parameters such as the inflation target reflects the widespread view that lower growth is in fact due to a persistent structural change rather than temporary factors that can be addressed by monetary policy without an overhaul of the policy framework. At the same time, while the period of low growth is persistent, the US economy has experienced repeated and lengthy periods of high or low growth (Fernald, 2012; Foerster and Matthes, 2020). This fact suggests that at some point in the future, the economy may return to a period of higher growth, only to switch back to a period of lower growth again at a later date.

Periods of higher or lower growth affect the conduct of monetary policy through direct effects on output and inflation, but also indirectly through the connection between growth and the real interest rate. If growth is persistently low, then an associated low real interest rate provides some justification for increasing the inflation target: a higher inflation target is intended to increase the nominal interest rate in order to avoid hitting the zero lower bound, at which time central banks may have to use unconventional policy such as forward guidance or quantitative easing. However, adjusting the inflation target due to structural change requires two important considerations.

First, moving the inflation target is only one of possibly multiple adjustments to the conduct of monetary policy that can be made. Rather than focusing solely on the inflation target, it makes sense to also consider how strongly the nominal rate should react to current conditions versus have inertia in policy, as this systematic feature may have trade-offs relative to moving the target. Higher degrees of inertia increase the memory of the interest rate process, and thereby become more like a price-level target where past deviations of inflation are compensated for rather than ignored. On the other hand, very high levels of inertia lead to interest rates behaving more like a peg where they do not respond to inflation, increasing macroeconomic volatility.

Second, another issue for changing monetary policy due to structural change is that the

economy tends to shift between periods of high and low growth. These repeated regime changes 
may not occur very frequently, but are not impossible. A monetary authority should account for the possibility of future shifts in the growth rate when setting policy. In addition, if the monetary authority is changing how it reacts as the economy undergoes structural shifts, then households and firms will respond to these policy shifts, leading to feedback effects.

This paper studies optimal simple rules for monetary policy when the structural economy experiences regime shifts. Using a standard New Keynesian model modified so that growth rate switches between high and low growth regimes, it assesses the implications for setting the inflation target and degree of interest rate inertia when monetary policy follows a Taylor rule and is subject to the zero lower bound. The switching in the growth rate process tends to generate a low real interest rate in one of the regimes, which affects inflation and output dynamics. This change in dynamics causes the monetary authority to need to adjust its policy parameters to avoid the zero bound. The non-linearity resulting from the zero lower bound plays a key role. If nominal rates were not bounded below at zero, a decrease in the trend growth rate would simply imply a decrease in the real interest rate target by a proportional amount; the optimal policy parameters would remain unaffected. However, with a binding zero bound, the monetary authority is unable to provide additional accommodation when armed only with an interest rate rule. This inability of the monetary authority to operate further lower rates induces adjustment in the optimal policy parameters.

The focus on the inflation target and inertia is because these two options present a trade-off for the monetary authority. A higher inflation target raises the level of the nominal rate when the real rate is low, which tends to keep the nominal rate positive, but comes at the cost of higher inflation. On the other hand, making interest rates more inertial and hence dampening their responsiveness to current conditions can keep interest rates stable at positive values at the cost of injecting more volatility into inflation and output. Higher degrees of inertia can also generate lower-for-longer nominal rate dynamics that provide additional stimulus when at the zero lower bound (Nakata and Schmidt, 2019). An optimizing monetary authority that follows a rule will set both of these policy parameters in tandem depending on the growth rate. Focusing on only one, for instance the inflation target, ignores a key degree of freedom available in setting monetary policy. More specifically, comparing optimal rules between a high and low growth rate economy, the optimal rule for low growth has a slightly higher inflation target and more inertia; ignoring the possibility of an increase in inertia would cause the monetary authority to set an even higher inflation target.

In addition, taking repeated switches between high and low growth into account is a key consideration for setting policy. The monetary authority can generate better welfare by inter- 
nalizing expectation effects. These effects include the direct effects that switching between high and low growth regimes has on monetary policy through household and firm behavior, but also the fact that if the monetary rule changes across regimes, households and firms will internalize the possibility of future policy changes. In other words, communication of a switching policy has effects beyond the current rule set in place. As a result, the optimal inflation target and degree of inertia are similar but not exactly the same as the optimal parameters if each regime occurred in isolation without switching behavior.

One possible caveat to switching monetary policy rules due to structural change is that implementing the correct rule at the correct time may be difficult. For example, Hachem and Wu (2017) use heterogeneous inflation expectations that are updated through social dynamics to study why abrupt changes in inflation targets may not be successfully achieved. In this paper's framework, the difficulty may arise due to the monetary authority misidentifying the growth regime and using the incorrect rule, or due to the authority making a mistake and simply failing to adopt the proper rule. Such an outcome could be costly from a welfare perspective. Under these circumstances, setting an optimal constant rule that is not susceptible to such errors could be preferred if the incidence of implementing the correct rule is relatively high. This result then suggests that providing flexibility for a monetary policy rule can generate gains, but if errors occur with high enough frequency the constant rule is preferred.

Much of the literature on optimal monetary policy with simple rules assumes a constant economic environment and constant rules over time. Schmitt-Grohe and Uribe (2007) characterize optimal simple rules in an economy without instability in the structural economy, and show these rules nearly replicate welfare achieved by a Ramsey planner. Nakov (2008) studies simple rules in the presence of the zero lower bound, and finds their performance is largely unaffected by the bound. In the context of regime switches in the structural economy, this paper shows simple rules that switch alongside the structural economy welfare can dominate fixed rules.

More recently, there has been considerable discussion about whether to change inflation targets in light of lower growth and real interest rates. For example, Rogoff (2008), Blanchard et al. (2010), and Ball (2013) all call for higher inflation targets in the United States. Billi (2011), Coibion et al. (2012), Dordal-i-Carreras et al. (2016) and Blanco (2018) consider the optimal inflation target in the presence of the zero lower bound on the nominal interest rate. In these cases, the monetary authority sets a constant inflation target that weighs the costs of higher inflation against the chance of hitting the zero lower bound. The optimal simple rules considered in this paper allow this trade-off to be regime-dependent, which enables the authority to set a higher inflation target in regimes where hitting the zero bound is relatively more likely. 
The focus in this paper on the trade-off between inflation targets and inertia also suggests that optimizing over only the target can produce more drastic changes in inflation targets than is necessary.

Recent experience with extended zero lower bound episodes in the United States and across the world led to much research studying the dynamics of economies at or near the bound. In this extensive literature, this paper relates most closely to Nakata and Schmidt (2019), who study how including a interest rate smoothing objective for a discretionary monetary authority can improve outcomes by keeping the nominal rate lower for longer. These dynamics affect the inertia versus inflation target trade-off considered in this paper. In addition, Bianchi et al. (2019) study an asymmetric rule to improve outcomes that come from the zero lower bound constraint. The presence of deflationary spirals plays an important role in that analysis; these spirals are situations where monetary policy cannot stabilize inflation at the bound, leading to self-fulfilling lower inflation. The analysis in this paper finds theses spirals arise for certain choices of the target or inertia, restricting the parameters that an optimal monetary policy rule can take.

Papers studying switching in monetary policy rules often have non-optimal switches that are independent of any underlying changes in the economy. Davig and Leeper (2007) and Bianchi (2013) consider switches in the coefficients dictating how the monetary authority responds to deviations from its targets. Schorfheide (2005) and Liu et al. (2011) allow for switches in the inflation target, and Foerster (2016) considers both types. However, in each of these frameworks, changes in the monetary policy rule occur randomly and without regard to the state of the private economy. In contrast, this paper motivates regime switching in the policy rule as an optimal response to switches in the private economy.

In the case where papers consider optimal policy with regime switching in the private economy, the monetary authority may face a reduced-form representation of the structural economy as in Blake and Zampolli (2011). On the other hand, Debortoli and Nunes (2014) interpret regime switching in monetary policy as coming from explicit changes in the authority's loss function. Davig (2016) shows how regime switches in price-setting behavior in the structural economy map into switches in the loss function when the authority operates with discretion. In contrast to these frameworks, this paper considers optimal simple rules, and how changes in the structural economy affect the optimal choice of policy parameters.

A caveat to the analysis in the paper is that it ignores explicit consideration of unconventional policy. A number of papers study the economic effects of quantitative easing (Hamilton and Wu, 2012; Gertler and Karadi, 2013; Greenwood and Vayanos, 2014) or forward guidance 
(Negro et al., 2012; McKay et al., 2016). Sims and Wu (2019) build a model that compares the effects of forward guidance and quantitative easing, and Wu and Xia (2016) develop a measure that summarizes multiple forms of unconventional accommodation. While this paper does not explicitly consider these additional channels for monetary policy, it does consider the implications of different simple rules for the long-term interest rate when at the zero bound. This rate can be viewed as a proxy for when unconventional policy might be more effective. In addition, the fact that higher inertia produces lower-for-longer dynamics at the zero lower bound mimics forms of forward guidance.

The remainder of the paper proceeds as follows: Section 2 presents the model, Section 3 shows results for optimal policy rules without regime switching, Section 4 considers optimal policy rules in the presence of regime switches, Section 5 studies the effects of monetary policy errors, and Section 6 concludes.

\section{Model}

This section describes a prototypical New Keynesian model. The four key features of the model are: (i) nominal rigidities without indexation of prices that create a role for inflation stabilization near price stability, (ii) a preference shock that affects the inter-temporal decisions of the household, (iii) regime switching that affects the growth rate of the economy, and (iv) a monetary authority with only access to a Taylor rule for setting nominal interest rates that is constrained by the zero lower bound.

The following presents the model's several parts: households, final and intermediate goods firms, fiscal policy and the aggregate resource constraint, the monetary authority, and how regimes switch. The Section ends with a discussion of welfare, and the calibration and solution method. A full set of derivations for the model is included in the Online-Only Appendix.

\subsection{Households}

Households maximize lifetime expected discounted utility of the form

$$
\mathbb{E}_{0} \sum_{t=0}^{\infty} \beta^{t} d_{t}\left(\log \left(C_{t} / A_{t}\right)-\frac{\phi}{1+\phi} H_{t}^{\frac{1+\phi}{\phi}}\right)
$$

where $\mathbb{E}_{0}$ is the expectations operator conditional on information at time $0, \beta$ is the discount factor, $C_{t}$ is consumption, $A_{t}$ is the level of technology, $H_{t}$ is hours worked, and $\phi$ denotes the 
Frisch elasticity. The inter-temporal preference shifter $d_{t}$ follows

$$
\log d_{t}=\rho_{d} \log d_{t-1}+\sigma_{d} \varepsilon_{d, t} .
$$

Households face the budget constraint

$$
C_{t}+\frac{B_{t}}{P_{t}}+T_{t}=W_{t} H_{t}+R_{t-1} \frac{B_{t-1}}{P_{t}}+D_{t},
$$

where $B_{t}$ denotes bonds purchased at time $t$ that pay out a gross nominal interest rate $R_{t}$ at $t+1, T_{t}$ is real lump-sum taxes paid to the government, $W_{t}$ is the real wage rate, and $D_{t}$ is real dividend payments from firms.

Standard optimality conditions for the household produce an Euler equation of the form

$$
\beta \mathbb{E}_{t}\left(\frac{C_{t}}{C_{t+1}}\right)\left(\frac{d_{t+1}}{d_{t}}\right) \frac{R_{t}}{\Pi_{t+1}}=1,
$$

which highlights how, all else equal, shocks or regime shifts that decrease the growth rate of consumption will increase the term $C_{t} / C_{t+1}$ and hence will tend to lower the nominal interest rate. Likewise, given the autoregressive process in equation (2), negative realizations of $\varepsilon_{d, t}$ will tend to increase $d_{t+1} / d_{t}$, which, all else equal, will then tend to lower $R_{t}$.

\section{$2.2 \quad$ Firms}

There are two types of firms: intermediate goods firms that produce with labor, and final good firms that bundle intermediate goods into a final output to be consumed by households and the government.

A competitive final good producer combines a continuum of intermediate goods $Y_{j, t}, j \in[0,1]$, by a constant elasticity of substitution technology to produce a final good

$$
Y_{t}=\left(\int_{0}^{1} Y_{j, t}^{\frac{1}{1+\mu}} d j\right)^{1+\mu},
$$

where $\mu$ denotes the net markup. This specification implies the demand for a good $Y_{j, t}$ depends on its relative price, the markup, and aggregate demand by

$$
Y_{j, t}=\left(\frac{P_{j, t}}{P_{t}}\right)^{-\frac{1+\mu}{\mu}} Y_{t} .
$$


Intermediate goods producers are indexed by $j$ and have production functions

$$
Y_{j, t}=A_{t} H_{j, t},
$$

where total factor productivity growth follows a regime-switching process

$$
\Delta \log A_{t}=\log \omega\left(s_{t}\right)+\sigma_{a} \varepsilon_{a, t},
$$

The mean growth rate of TFP, $\omega\left(s_{t}\right)$, switches with the regime variable $s_{t}$ to be discussed in detail shortly.

Intermediate goods firms adjust prices according to Rotemberg pricing without indexation of prices to inflation. Consequently, the firm's maximization problem is to choose $H_{j, t}$ and $P_{j, t}$ to maximize

$$
\mathbb{E}_{0} \sum_{t=0}^{\infty} \beta^{t} \frac{\lambda_{t}}{\lambda_{0} P_{t}}\left(\left(\frac{P_{j, t}}{P_{t}}\right)^{-\frac{1}{\mu}} Y_{t}-W_{t} H_{j, t}-\frac{\gamma}{2}\left(\frac{P_{j, t}}{P_{j, t-1}}-1\right)^{2} Y_{t}\right)
$$

where $\lambda_{t}$ denotes the marginal utility of consumption for the household, and $\gamma$ determines the cost of adjusting prices. Firms are also subject to the constraint that supply (7) must meet demand (6) at the posted price. The price adjustment generates a cost of inflation in output terms, as deviations from price stability generate progressively higher losses in output.

\subsection{Fiscal Policy and Aggregate Resource Constraint}

The government purchases a constant fraction $\zeta$ of aggregate output $Y_{t}$, so government spending is $G_{t}=\zeta Y_{t}$. The government collects lump-sum taxes to cover spending, and nominal bonds are in zero net supply. Importantly, fiscal policy does not have access to a production subsidy to firms that eliminates the distortions associated with monopolistic competition; the inefficiency from imperfect competition must be taken into account by the monetary authority when setting policy (Woodford, 2003).

The aggregate resource constraint is given by

$$
Y_{t}=C_{t}+G_{t}+\frac{\gamma}{2}\left(\Pi_{t}-1\right)^{2} Y_{t} .
$$

This resource constraint again highlights the cost of inflation, as deviations from price stability produce losses in output that cannot go to consumption or the government. Moreover, this cost is high when output is high, so changes in the growth rate of technology have implications for 
the costliness of price changes.

\subsection{Monetary Policy}

The monetary authority sets the nominal interest rate bound using a Taylor rule of the form

$$
\frac{Z_{t}}{R_{t}^{*}}=\left(\frac{Z_{t-1}}{R_{t}^{*}}\right)^{\psi_{r}\left(s_{t}\right)}\left(\left(\frac{\Pi_{t}}{\Pi^{*}\left(s_{t}\right)}\right)^{\psi_{\pi}}\left(\frac{\tilde{Y}_{t}}{\tilde{Y}_{s s}}\right)^{\psi_{y}}\right)^{1-\psi_{r}\left(s_{t}\right)}
$$

where $Z_{t}$ is a shadow rate. The nominal rate is subject to the zero lower bound

$$
R_{t}=\max \left\{Z_{t}, 1\right\}
$$

This form allows for regime switches in the inflation target $\Pi^{*}\left(s_{t}\right)$ and the degree of interest rate inertia $\psi_{r}\left(s_{t}\right)$, which change according to the regime $s_{t}$. The rule has a constant responsiveness to inflation and output deviations from steady state, $\psi_{\pi}$ and $\psi_{y}$, respectively. The output deviation is in terms of de-trended output $\tilde{Y}_{t}=Y_{t} / A_{t}$ from its steady state value $\tilde{Y}_{s s}$. The reasons to require $\psi_{\pi}$ and $\psi_{y}$ to remain fixed across regimes is that optimal policy typically places significant weight on inflation stabilization around target, and a low weight on the output gap, and these incentives are similar across regimes. ${ }^{1}$

Note that the above has a time-varying neutral nominal rate $R_{t}^{*}$, which follows

$$
R_{t}^{*}=\Pi^{*}\left(s_{t}\right) \frac{\omega\left(s_{t}\right)}{\beta},
$$

and is made up of the inflation target, $\Pi^{*}\left(s_{t}\right)$, and the steady state real rate that would prevail if each regime occurred in isolation, which is in turn a function of the growth rate of the economy.

\subsection{Regime Switching}

As noted, the structural economy experiences switches in the growth rate of TFP, $\omega\left(s_{t}\right)$. The variable $s_{t}$ denotes the growth regime and takes one of two values $s_{t} \in\{H, L\}$, where $H$ denotes high growth and $L$ denotes low growth. The regime follows a Markov processes governed by a

\footnotetext{
${ }^{1}$ In an earlier version of this paper, analysis of the model that allowed switching inflation and output responses found the inflation response went to the maximal permitted value and the output response was low, and these did not change across regimes. Thus, this paper focuses on the policy parameters that have meaningful differences across regimes.
} 
transition matrix with elements $p_{i j}=\operatorname{Pr}\left(s_{t}=j \mid s_{t-1}=i\right)$ :

$$
P=\left[\begin{array}{cc}
p_{H H} & 1-p_{H H} \\
1-p_{L L} & p_{L L}
\end{array}\right]
$$

At the same time, the monetary authority switches the parameters $\psi_{r}\left(s_{t}\right)$ and $\Pi^{*}\left(s_{t}\right)$ to reflect the new growth regime.

\subsection{Welfare and Optimal Policy Rules}

Given the economic structure, the monetary policy sets policy parameters for the Taylor rule given by equation (11). First, they have a given inflation response $\psi_{\pi}$ and output gap response $\psi_{y}$ that do not change across regimes. More substantively, the monetary authority can set the degree of inertia $\psi_{r}\left(s_{t}\right)$ and the inflation target $\Pi^{*}\left(s_{t}\right)$ across regimes. These two parameters have important implications across regimes. The inflation target affects the level of inflation and hence the level of the nominal rate. On the other hand, the degree of inertia affects the volatility of the nominal rate and hence of inflation and output.

Among the set of policy parameters, the monetary authority chooses those that are optimal in the sense that they maximize the household's expected lifetime utility,

$$
\mathbb{E}\left[V_{0}\right]=\mathbb{E} \sum_{t=0}^{\infty} \beta^{t} d_{t}\left(\log \left(C_{t} / A_{t}\right)-\frac{\phi}{1+\phi} H_{t}^{\frac{1+\phi}{\phi}}\right)
$$

By using the household's preferences, the monetary authority is making optimal policy from the household's perspective, rather than holding its own objective function. The monetary authority uses the unconditional expectation of welfare rather than using a single point or regime combination as an initial condition. ${ }^{2}$

As a benchmark for welfare comparisons, the results in Sections 3-5 use the steady state of the Ramsey planner's problem. The Ramsey planner sets the nominal interest rate in a fully state-contingent manner, without being constrained to following a Taylor rule as in equation (11). In a version of the model without the zero lower bound, the Ramsey planner conducts policy to fully offset the effects of shocks, which leaves inflation and output constant. The results report the consumption equivalent loss relative to the Ramsey steady state: the loss in Ramsey

\footnotetext{
${ }^{2}$ An alternative would be to condition the starting welfare on each of the two growth regimes, and some point for the state variables. The specific parameters chosen can be slightly numerically different-which highlights possible time-inconsistencies in choosing optimal rules-but gives qualitatively similar results.
} 
Table 1: Fixed Parameters

\begin{tabular}{l|l}
\hline \hline Description & \multicolumn{1}{l}{ Parameter Value } \\
\hline Discount Factor & $\beta=0.9987$ \\
Frisch Elasticity & $\phi=1$ \\
Fraction of Government Purchases & $\zeta=0.2$ \\
Net Markup & $\mu=0.10$ \\
Cost of Price Adjustment & $\gamma=100$ \\
Inter-temporal Preference Shock Persistence & $\rho_{d}=0.60$ \\
Technology Shock Std Dev (\%) & $\sigma_{a}=0.7$ \\
Inter-temporal Preference Shock Std Dev (\%) & $\sigma_{d}=1.0$ \\
Growth Rate, High Growth Regime (pp, annual) & $\omega(H)=2.0$ \\
Growth Rate, Low Growth Regime (pp, annual) & $\omega(L)=0.5$ \\
Transition Probabilities & $p_{L L}=p_{H H}=0.98$ \\
Monetary Policy Inflation Response & $\psi_{\pi}=2.5$ \\
Monetary Policy Output Response & $\psi_{y}=0.25$ \\
\hline \hline
\end{tabular}

steady state consumption that makes the household indifferent to being in the economy with a Taylor rule subject to the zero lower bound. ${ }^{3}$ As Schmitt-Grohe and Uribe (2007) highlight, the Taylor rule nearly replicates the Ramsey welfare levels in a model without switches or the zero lower bound. The following results, by showing the losses are quite small, indicate that this near equivalency carries into the environment with regime switches and the zero lower bound.

\subsection{Calibration}

The set of parameters shown in Table 1 describe preferences and production assuming the unit of time is a quarter. For the growth processes, the parameterization is in line the sub-sample analysis of Fernald (2012), who notes that productivity growth has switched between periods of high average growth rates of around 2 percent per year, and periods of low average growth rates of around 0.5 percent per year. The estimates in Foerster and Matthes (2020) confirm that productivity growth indeed follows a regime-switching process with two average growth regimes, with estimates similar to Fernald (2012). The transition probabilities imply each regime has an expected duration of 12.5 years, which is roughly in line with both Fernald (2012) and Foerster and Matthes (2020).

More broadly, the growth regimes capture concerns about switches to slower growth regimes (Gordon, 2012), as well as to a lower real interest rate (Summers, 2014). The presence of

\footnotetext{
${ }^{3}$ See the Online-Only Appendix for additional details.
} 
growth rate switches affects the household's Euler equation (4) and the intermediate goods firms' problem via technology (7). In addition, lower growth also changes the neutral nominal rate in the monetary policy rule (13), by affecting the real interest rate. In the low growth regime, the real rate tends to be low, which corresponds to a lower-and hence a greater chance of negative-nominal rate.

\subsection{Solution Method}

Given the multiple sources of nonlinearities in the economy, including the regime-switching and the zero lower bound, the results use the time iteration method of Coleman (1990). This fully global solution method captures both regime-switching and zero lower bound dynamics (Richter et al., 2014). Importantly, it captures the expectation effects that are particularly important in regime-switching contexts (Liu et al., 2009; Foerster, 2016), and incorporates precautionary motives generated by the presence of the zero lower bound even when the nominal rate is positive.

While the global solution method captures important features of the economic environment, it can also fail to converge or converge to an equilibrium that implies deflationary spirals (Bianchi et al., 2019). In these deflationary spirals, the monetary authority fails to stabilize inflation at the zero lower bound, leading to lower inflation expectations even away from the zero bound, which reinforces the deflation dynamics. When these episodes occur, the welfare losses are infinite since economic activity collapses, meaning the monetary authority needs to pick policy parameters that generate a viable equilibrium that avoids these spirals.

\section{Optimal Monetary Policy without Regime Switches}

Before analyzing the economy with switches between growth regimes, this Section first analyzes optimal monetary policy rules without switching. The model therefore has two separate versions: one in which the average growth rate is always high, and one in which the average growth rate is always low. Comparisons between the optimal policy and its economic effects illustrate the trade-offs the monetary authority faces when setting its policy parameters.

\subsection{Optimal Rules without Regime Switches}

Given the framework discussed in Section 2, the monetary authority faces two key trade-offs when setting policy. First, the presence of nominal rigidities without price indexation implies a need to keep inflation low and stable; in particular, exact price stability minimizes the resource 
cost from inflation in equation (10). ${ }^{4}$ This incentive then suggests that the monetary authority will want to have an inflation target close to zero, and a rule with low inertia so that it can respond rapidly to deviations of inflation from target to maintain low and stable inflation.

On the other hand, the zero lower bound constraint on the nominal interest rate creates incentives to keep the nominal rate positive and limit the degree to which it fluctuates. A higher nominal rate with a lower variance will tend to have a lower frequency of hitting the zero lower bound, where it is unable to further respond to macroeconomic fluctuations. This incentive means that the monetary authority will tend to want to raise the inflation target or make the nominal rate more inertial when it is positive. These incentives work in contrast to the ability to keep inflation low and stable. In addition, when the nominal rate is at zero, higher inertia can produce dynamics that keep the nominal interest rate lower for longer, which helps provide additional monetary stimulus and mitigates the declines in inflation when the constraint binds (Nakata and Schmidt, 2019). In addition, the higher inertia tends to keep the nominal rate at zero for longer, and thus mimics some forms of forward guidance.

Figure 1 shows the trade-off the monetary authority faces in setting the policy parameters in each growth regime. First, considering the case of $2 \%$ growth, Figure 1a shows the optimal inflation target given a degree of interest rate inertia. The figure highlights a negative relationship between the inflation target and inertia when setting an optimal rule. In particular, depending on the degree of inertia, the optimal inflation target can range between 0 and around 0.4 percent. When the degree of inertia is low, the nominal rate fluctuates substantially to shocks. A slightly positive inflation target of around 0.4 percent is optimal in this case, as it helps mitigate the risk of hitting the zero lower bound. Higher inflation targets come at the cost of additional loss of resources from price-setting without indexation, while lower inflation targets come at the cost of higher frequency at the zero lower bound. As the degree of interest rate inertia increases, the optimal inflation target decreases; when inertia is sufficiently high, then a zero inflation target becomes optimal. Very high inertia exceeding 0.93, on the other hand, leads to peg-like conditions where the nominal rate does not move enough to offset fluctuations, and leads to no solution, indicating non-existence of an equilibrium.

The fully optimizing monetary authority takes this line of conditionally optimal relationships and chooses the parameter configuration that generates the highest welfare among them. As noted, low levels of inertia have more responsiveness to current conditions, but require higher

\footnotetext{
${ }^{4}$ The model does not contain features such as quality improvements or heterogeneity among individuals that might warrant higher inflation targets, so these inflation targets will tend to be low in absolute terms (SchmittGrohe and Uribe, 2010).
} 
Figure 1: Optimal Rules without Regime Switching

(a) High Growth

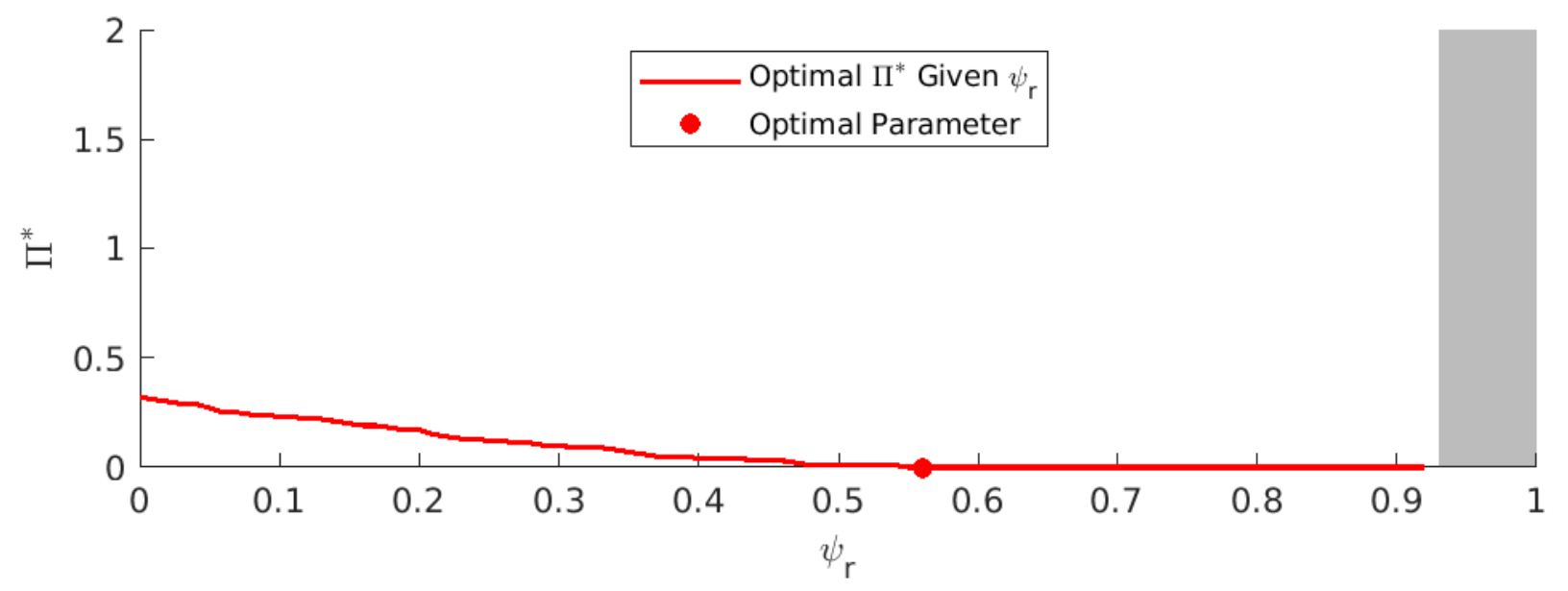

(b) Low Growth

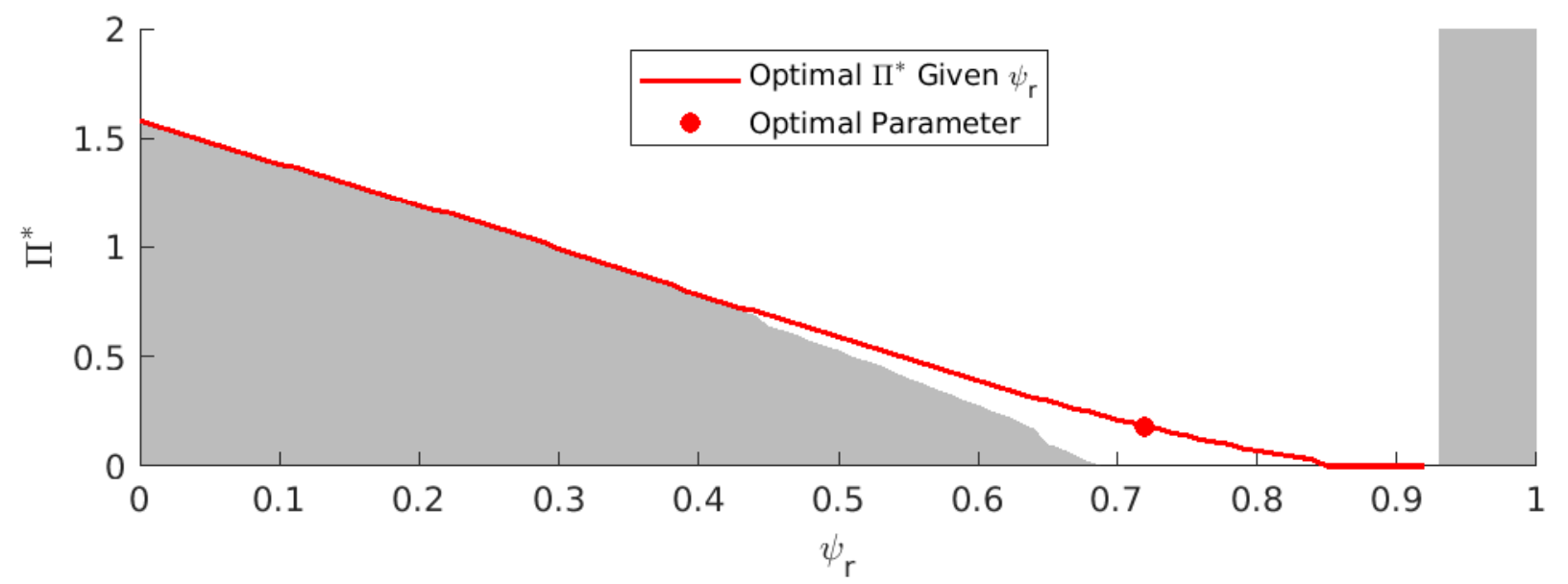

Note: Panel (a) shows the policy parameters without regime switching when growth is high. Panel (b) shows the policy parameters without regime switching when growth is low. Red line indicates the optimal inflation target $\Pi^{*}$ conditional on the smoothing parameter $\psi_{r}$, and the red dot shows the optimal choice of $\left(\Pi^{*}, \psi_{r}\right)$. Grey regions indicate no solution.

inflation targets. Higher levels of inertia can support a lower inflation target, generate lower-forlonger dynamics when at the zero lower bound, and lead to more macroeconomic volatility away from the bound. The monetary authority will end up picking an optimal rule with parameters of $\psi_{r}=0.56$ and $\Pi^{*}=0.0$, shown by the dot in Figure 1a and listed in Table 2. This target implies exact price stability in steady state, which minimizes the resource cost of inflation, and the inertia is the minimum degree of inertia that supports this target. In other words, lower 
Table 2: Optimal Policy Rules and Outcomes without Regime Switching

\begin{tabular}{l|cc|cc|cc|c}
\hline \hline & \multicolumn{2}{|c|}{ Parameters } & \multicolumn{2}{|c|}{ Mean (Std Dev) } & \multicolumn{2}{|c|}{ ZLB } & Welfare \\
Regime and Rule & $\psi_{r}$ & $\Pi^{*}$ & $\Pi_{t}$ & $R_{t}$ & Freq & $R_{t: t+40}$ & Loss \\
\hline High Growth Regime & & & & & & & \\
-Optimal High Rule & 0.56 & 0 & $-0.01(0.60)$ & $2.52(1.12)$ & 0.64 & 2.38 & -2.32 \\
-Optimal Low Rule & 0.72 & 0.18 & $0.18(0.59)$ & $2.72(0.83)$ & 0 & - & -3.68 \\
& & & & & & & \\
Low Growth Regime & & & & & & & \\
-Optimal High Rule & 0.56 & 0 & $-\infty$ & $0(0)$ & 100 & 0 & $-\infty$ \\
-Optimal Low Rule & 0.72 & 0.18 & $0.11(0.64)$ & $1.12(0.79)$ & 12.51 & 1.05 & -2.91 \\
-Only Opt. Target & 0.56 & 0.47 & $0.27(0.74)$ & $1.28(1.06)$ & 20.01 & 1.20 & -3.49 \\
\hline \hline
\end{tabular}

Note: The top panel shows the case when average growth is always high, and the bottom panel shows the case when average growth is always low. Means and standard standard deviation are shown in percent at an annual rate, zero lower bound frequency in percent, long-term rate in percent at an annual rate, and welfare loss is in basis points relative to the Ramsey steady state.

levels of inertia would necessitate a positive inflation target, whereas higher inertia brings no benefit in terms of a lower inflation target.

Now turning to the case with lower growth, Figure 1b shows that the line of conditionally optimal inflation target shifts upwards. The lower growth produces a lower real interest rate, which, all else equal, lowers the nominal rate and increases the incidence of the zero lower bound. As a result, the monetary authority needs to either raise the inflation target or increase the degree of interest rate inertia. In fact, for combinations of low inertia and low inflation targets, the incidence of the zero bound is so high that a deflationary spiral occurs, leading to no solution for the equilibrium. At low levels of inertia, avoiding a deflationary spiral becomes a binding constraint on choosing optimal policy, since without inertia changes in the inflation target have more dramatic effects on the level of inflation and incidence of the zero bound. At higher levels of inertia, the conditional optimal policy line is less constrained by the region of parameters that generates deflationary spirals. In the low growth case, the conditionally optimal inflation target line indicates that the targets between 0 and around 1.6 percent can be supported. The fully optimal combination of parameters is $\psi_{r}=0.72$ and $\Pi^{*}=0.18$, shown by the dot in Figure $1 \mathrm{~b}$ and listed in Table 2.

\subsection{Outcomes without Regime Switching}

Table 2 gives additional details on economic outcomes for different policy rules in each regime. First, considering the optimal high rule within the high growth regime, the policy parameters 
of $\psi_{r}=0.56$ and $\Pi^{*}=0$ generate price stability on average with zero inflation, and a relatively modest volatility of inflation. The high growth generates a high real interest rate, which leads to a nominal rate with a relatively high average, with a standard deviation low compared to the average. Consequently, there is a very low chance of hitting the zero bound: less than a 1 percent frequency. Further, when the economy is at the zero bound, the long-term interest rate out 40 quarters is near the unconditional mean. This longer-term interest rate, which might be a target rate if the monetary authority used unconventional policies that are not considered in this paper, indicates there is significant scope for additional stimulus in long-term interest rates. ${ }^{5}$ The welfare loss from following this policy rule is $2.32 \mathrm{bp}$ relative to the Ramsey steady state, as the Taylor rule generates outcomes that nearly replicate the welfare of a Ramsey planner who does not face any fluctuations.

The lower panel of Table 2 shows that if the economy moves from the high to the low growth case, it must change its rule in some dimension, as it cannot keep the optimal high rule. This result is because the high growth rule applied in the low growth case produces a deflationary spiral, as the inflation target or inertia needs to be increased to produce a valid equilibrium.

From an optimal policy perspective, it is important for the monetary authority to re-optimize both the inflation target and the degree of inertia. The trade-off between inertia and the inflation target implies that only re-optimizing on the inflation target dimension, which has been the subject of much study and discussion, can produce inferior economic outcomes. The lower panel of Table 2 shows that, if the economy moves from the high to the low growth regime, while keeping in place the optimal inertia from the high growth rule and only changing the inflation target, the inflation target would have to be increased to 0.47 percent, more than a double increase relative to the new optimal value of 0.18 percent. This increase in the inflation target would move the nominal rate up in order to decrease the incidence of hitting the zero bound and leading to a deflationary spiral. Whereas the optimal low rule has a welfare loss of $2.91 \mathrm{bp}$ relative to the Ramsey steady state, optimizing the target only leads to larger losses of nearly $3.5 \mathrm{bp}$. The reason for the greater welfare loss when only the target is re-optimized is that despite the higher inflation target, the lower inertia leads to more volatility of the nominal rate, which then produces a frequency of hitting the zero bound of 20 percent. By contrast, the optimal low rule raises the inertia, leading to a frequency of the zero bound of 12.5 percent. Therefore, in the event of a change from high to low growth, the monetary authority would need to consider

\footnotetext{
${ }^{5}$ The calculations for the longer-term interest rate rely on the expectations hypothesis, with $R_{t: t+40}=$ $\mathbb{E}_{t} \prod_{j=0}^{39} R_{t+j}$. This calculation ignores term premia, which may be an important consideration for unconventional policy.
} 
the trade-off between inertia in its rule and the inflation target, rather than focusing solely on a re-optimization of the inflation target.

A change in the other direction, from low growth to high growth, likewise requires a reoptimization of the policy parameters. However, in this case, the need to re-optimize is less apparent because the low growth rule does not produce deflationary spirals in the high growth regime. Instead, a monetary authority that did not re-optimize would simply find a higher real interest rate pushing up the nominal rate without any difference in inflation dynamics from the low growth regime. These dynamics would have sub-optimally high inflation that was too volatile, producing a welfare loss about 50 percent higher than if the inflation target and the inertia were at their optimal values.

Lastly, in the presence of monetary policy re-optimization, a change in the growth regime naturally produces different dynamics for inflation and the nominal rate. In the low growth regime, optimal parameters lead to higher, slightly more volatile inflation than in the high growth regime. The non-negligible frequency of hitting the zero bound in the low growth regime induces a downward bias in realized inflation (Hills et al., 2016); the monetary authority sets the target knowing this bias occurs and therefore increases the target to compensate. The nominal rate should also tend to be lower and less volatile under the optimal policy rule when growth is low. However, long-term interest rates when at the zero bound are much lower in the low growth regime, indicating that while the probability of hitting the bound is higher, there is also less scope for unconventional policies aimed at lowering those rates.

While the above discussion shows how optimal policy rules differ when growth is either low or high, it considers changes in the growth rate, and hence changes in monetary policy, as complete surprises. Given that regime switches in growth, and therefore monetary policy, do occur and repeat themselves, it is natural for households and firms to build expectations about regime changes into their decision-making process and hence alter macroeconomic dynamics. Setting policy coefficients must then take these changes into account; the next section turns to addressing this issue.

\section{Optimal Monetary Policy Regime Switches}

This section turns to analysis of setting optimal monetary policy rules in the presence of regime switching between high and low growth regimes. In this full version of the economic model, the growth rate switches between high and low average growth rates, which in turn affects macroeconomic dynamics directly but also through expectation effects. For example, when 
the economy is in the high growth regime, households and firms internalize the possibility of lower growth in the future, which affects their desire to consume, supply labor, and set prices; similarly, in the low growth regime, the expectation of a possible shift to higher growth will affect decision making.

In addition to the trade-offs of low and stable inflation and limiting zero lower bound incidences as discussed in the previous section, the monetary authority faces an additional trade-off with regime switches. Specifically, the presence of regime switches-in both the private economy and possibly the monetary policy rule-generate expectation effects (Davig and Leeper, 2007; Liu et al., 2009; Foerster, 2016) that the monetary authority must internalize when setting optimal policy. Expectation effects of regime switching alter the equilibrium outcomes based on how policy switches, and the monetary authority must take these effects into account. For example, in the case when the inflation target may switch between regimes, firms and households will internalize this switching, leading to differences in behavior and hence realized inflation relative to the case when regime changes do not exist. Under these circumstances, realized inflation in each regime may differ from that regime's inflation target, and the authority sets policy knowing this result will occur.

\subsection{Optimal Constant Rule}

First, consider the case where the growth rate changes between high and low growth regimes, but the monetary authority sets a constant rule. In this case, they set the shadow nominal rate according to a fixed-parameter version of equation (11):

$$
\frac{Z_{t}}{R_{s s}^{*}}=\left(\frac{Z_{t-1}}{R_{s s}^{*}}\right)^{\psi_{r}}\left(\left(\frac{\Pi_{t}}{\Pi^{*}}\right)^{\psi_{\pi}}\left(\frac{\tilde{Y}_{t}}{\tilde{Y}_{s s}}\right)^{\psi_{y}}\right)^{1-\psi_{r}} .
$$

For this rule, the interest rate inertia and inflation target are unchanged when the growth regime changes, and the monetary authority sets the nominal rate according to deviations from the steady state nominal rate $R_{s s}^{*}=\Pi^{*} \bar{\omega} / \beta$, where $\bar{\omega}$ is the ergodic mean of $\omega\left(s_{t}\right)$. In other words, the monetary authority does not adjust the real interest rate implicit in its neutral nominal rate as the regime changes, but instead targets an average real rate plus its inflation target.

Figure 2 shows the trade-off between setting an inflation target and the interest rate inertia in the regime-switching case with a constant monetary policy rule. Similar to the case without regime switching, the monetary authority faces a choice between increasing the inflation target 
Figure 2: Optimal Constant Rules with Regime Switching

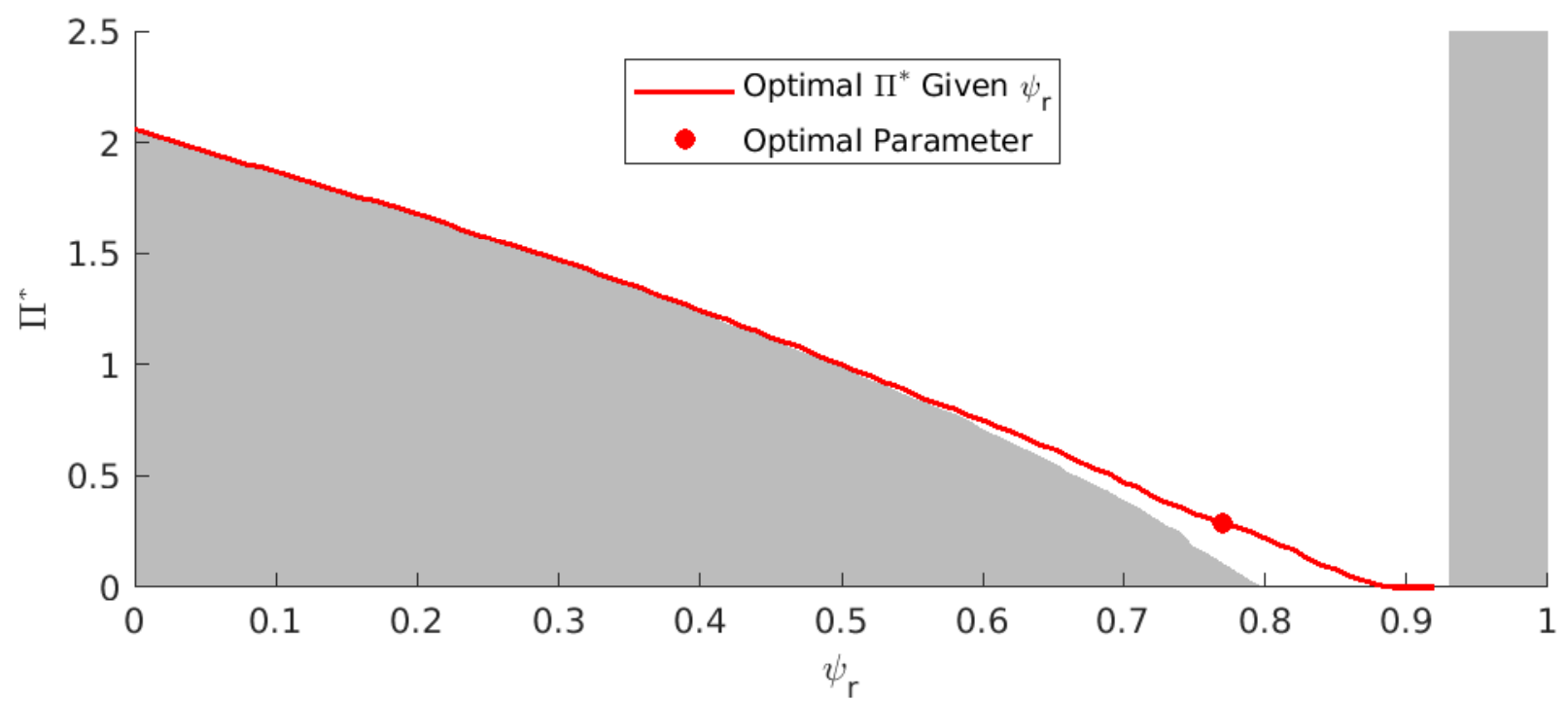

Note: Figure shows the policy parameters for a constant rule, when growth switches between high and low regimes. Red line indicates the optimal inflation target $\Pi^{*}$ conditional on the smoothing parameter $\psi_{r}$, and the red dot shows the optimal choice of $\left(\Pi^{*}, \psi_{r}\right)$. Grey regions indicate no solution.

and raising the degree of inertia. The exact nature of the trade-off in this case depends on dynamics in both regimes. In particular, the set of parameters that generates no solution due to a deflationary spiral is larger than for either of the fixed regime cases. Intuitively, for a fixed inertia choice, the monetary authority needs to have a higher inflation target than if either regime occurred in isolation. This result is due to the fact that the constant rule leads to a relatively high nominal rate during the low growth regime, which suppresses economic activity and leads to low inflation that can spiral out of control. A higher inflation target directly helps in the low growth regime by increasing the level of inflation and pushing the nominal rate away from zero. It also works indirectly during the high growth regime by inducing higher inflation when growth is high, which affects the low growth regime dynamics through expectations.

In the case of a constant rule, an inflation target between 0 and over 2 percent can be justified depending upon the level of inertia. As in the case without regime switching, the trade-off implies the inflation target can be lowered as inertia increases. The optimal policy parameters in this case, shown in Table 3 as well, are $\psi_{r}=0.77$ and $\Pi^{*}=0.29$. Both of these parameters exceed their values in either regime in the no switching case. 


\subsection{Optimal Switching Rule}

When the monetary policy rule switches fully, it changes inflation targets, inertia, and the real interest rate used to determine the neutral nominal rate. The optimal parameters are relatively close to the fixed rule parameters, with the welfare maximizing parameters given by $\psi_{r}(H)=0.55, \psi_{r}(L)=0.70, \Pi^{*}(H)=0.06$, and $\Pi^{*}(L)=0.15$. With four parameters to optimize over, the set of conditionally optimal parameters becomes multi-dimensional objects; Figure 3 shows slices of these objects, keeping two parameters fixed at their optimal values.

Figures $3 \mathrm{a}$ and $3 \mathrm{~b}$ show the within-regime trade-off between inertia and inflation targets in the high and low growth regimes, respectively. Analogous to Figure 1, the plots show the optimal inflation target conditional on the degree of inertia. The lines of conditionally optimal points and the range of parameters that generate no solution are similar to the no switching case. Lower levels of inertia in each regime are associated with higher inflation targets. However, the presence of regime switching implies spillovers between regimes that affect the optimal values slightly. For instance, with regime switching the maximum value of an optimal inflation target is less than 1.5 in the low regime, and a zero inflation target in that regime cannot be rationalized given any level of inertia. These plots also implicitly shows the importance of exploiting the trade-off between inertia and the inflation target in both regimes, as a monetary authority forced to pick a constant inertia level of 0.56 would need to have a higher inflation target in the low growth regime than is optimal.

Figures $3 c$ shows the trade-off between inertia across regimes. In particular, it displays the optimal choice of $\psi_{r}(L)$, conditional on different values for $\psi_{r}(H)$. Changes in one inertia parameter, say $\psi_{r}(H)$, have competing effects: lower inertia can makes inflation more volatile within the high growth regime, which can spill over and make inflation in the low growth regime more volatile as well; alternatively, the relatively stronger response to current conditions that comes with lower inertia can dampen the volatility of inflation in the low growth regime. There is thus a slight negative relationship between inertia parameters due to the relatively small probability of switching regimes. As $\psi_{r}(H)$ increases, then the optimal choice of $\psi_{r}(L)$ decreases slightly. This dynamic also holds for the boundary of the deflationary spiral region, as the same trade-off ensures a viable equilibrium exists.

Figure 3d shows the trade-off between the inflation target in both regimes. The switching in the real interest rate used for the neutral nominal rate allows for relatively low inflation targets across regimes. These targets are more in line with the optimal targets in the no switching case than the optimal target with a constant rule. As noted, the low inflation targets help minimize the resource cost of inflation that comes with deviations from price stability. Nevertheless, as 
Figure 3: Optimal Switching Rules with Regime Switching

(a) High Growth Regime

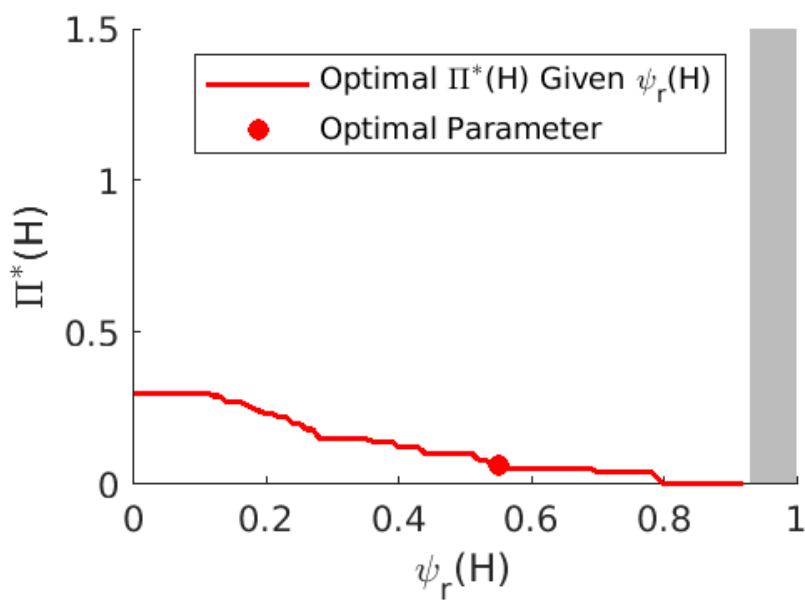

(c) Smoothing

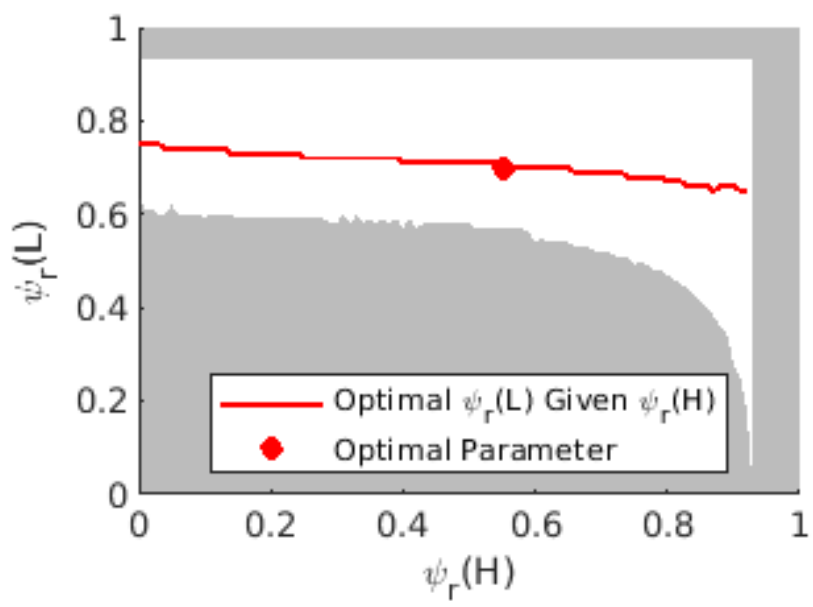

(b) Low Growth Regime

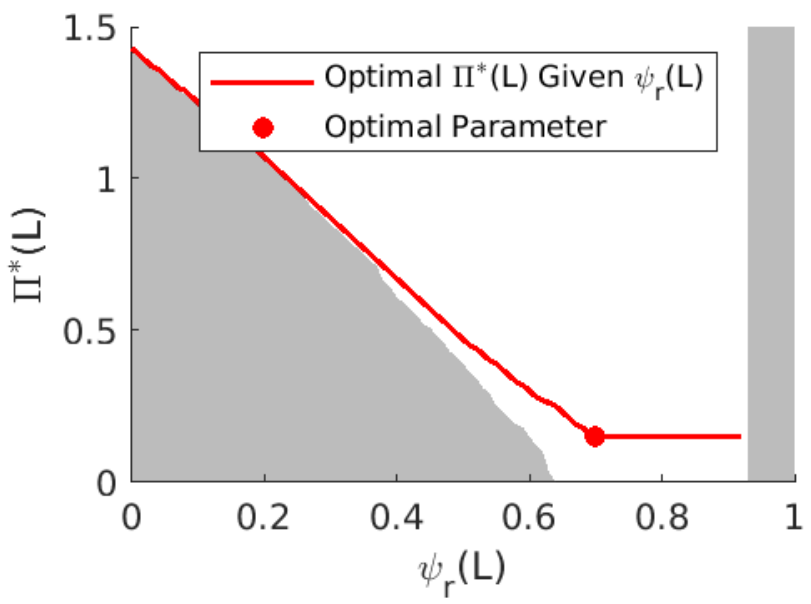

(d) Inflation Targets

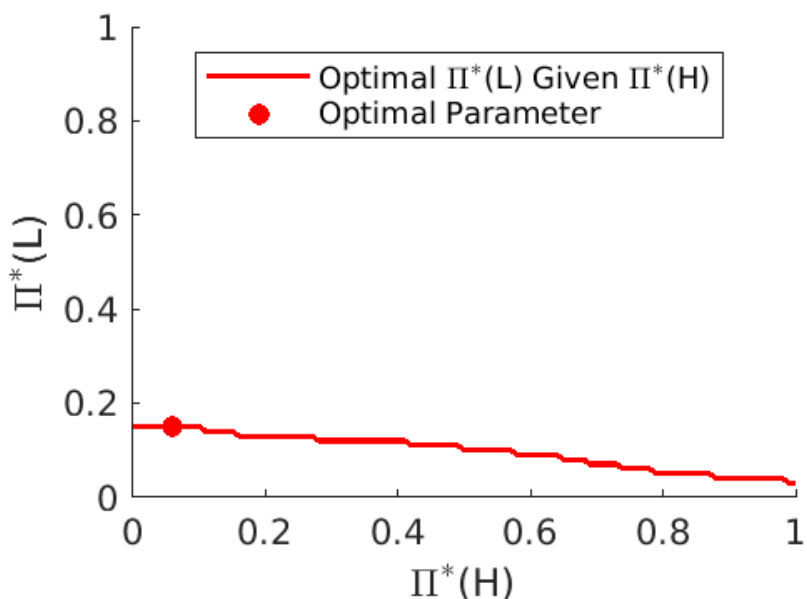

Note: Figure shows the policy parameters for a switching rule, when growth switches between high and low regimes, conditional on other parameters being at optimal values. For each panel, the red line shows the optimal choice of parameter on the y-axis, conditional on the parameter on the x-axis, and the red dot shows the optimal parameter. Optimal parameter is $\psi_{r}(H)=0.55, \psi_{r}(L)=0.70, \Pi^{*}(H)=0.06$, and $\Pi^{*}(L)=0.15$. Grey regions indicate no solution.

the high regime inflation target $\Pi^{*}(H)$ increases, the higher inflation in the high growth regime generates spillovers across regimes, which allow for a slight reduction in $\Pi^{*}(L)$. 
Table 3: Optimal Policy Rules and Outcomes with Regime Switching

\begin{tabular}{l|cc|cc|cc|c}
\hline \hline & \multicolumn{2}{|c|}{ Parameters } & \multicolumn{2}{|c|}{ Mean (Std Dev) } & \multicolumn{2}{c|}{ ZLB } & Welfare \\
Rule & $\psi_{r}\left(s_{t}\right)$ & $\Pi^{*}\left(s_{t}\right)$ & $\Pi_{t}$ & $R_{t}$ & Freq & $R_{t: t+40}$ & Loss \\
\hline Naive Switching Rule & & & & & & & \\
-Overall & & & $0.05(0.62)$ & $1.81(1.13)$ & 5.35 & 1.50 & -2.60 \\
-In High Regime & 0.56 & 0 & $-0.07(0.59)$ & $2.39(1.1)$ & 1.03 & 2.27 & \\
-In Low Regime & 0.72 & 0.18 & $0.17(0.63)$ & $1.23(0.81)$ & 9.76 & 1.15 & \\
& & & & & & & \\
Optimal Constant Rule & & & & & & & \\
-Overall & & & $0.24(0.91)$ & $2.01(1.38)$ & 9.19 & 1.34 & -5.10 \\
-In High Regime & 0.77 & 0.29 & $0.82(0.60)$ & $3.22(0.74)$ & 0 & - & \\
-In Low Regime & 0.77 & 0.29 & $-0.35(0.67)$ & $0.8(0.66)$ & 19.27 & 0.74 & \\
& & & & & & & \\
Optimal Switching Rule & & & & & & & \\
-Overall & & & $0.05(0.63)$ & $1.82(1.17)$ & 6.65 & 1.47 & -2.58 \\
-In High Regime & 0.55 & 0.06 & $-0.02(0.59)$ & $2.45(1.12)$ & 0.95 & 2.32 & \\
-In Low Regime & 0.70 & 0.15 & $0.12(0.65)$ & $1.18(0.84)$ & 12.75 & 1.10 & \\
\hline \hline
\end{tabular}

Note: Top panel shows the naive switching rule, middle panel shows the optimal constant rule, and bottom panel shows the optimal switching rule. Parameters conditional on each regime shown for each rule. Outcomes shown are either in full model (overall), or conditional on being in the high or low growth regime. Means and standard standard deviation are shown in percent at an annual rate, zero lower bound frequency in percent, long-term rate in percent at an annual rate, and welfare loss is in basis points relative to the Ramsey steady state.

\subsection{Outcomes with Regime Switching}

Table 3 shows the economic outcomes for three different rules in the presence of regime switching. The first is a naive switching rule, where the monetary authority simply applies the optimal rules derived in the case without regime switching discussed in Section 3. The second rule is the optimal constant rule, and the third is the optimal switching rule. The table shows economic outcomes in an overall sense that accounts for switches between regimes, as well as the conditional outcomes within each regime.

First, the naive switching rule, when compared with the optimal high and optimal low rules in Table 2, illustrates the effects of switching in the growth rate directly. Without switching, recall that the optimal high rule led to price stability, an average nominal rate of around 2.5 , and a frequency of hitting the zero bound of $0.64 \%$. The optimal low rule had a higher inflation rate, lower and less volatility nominal rate, and a zero bound frequency of $12.5 \%$. Regime switching leads to slightly different outcomes. In the high regime, the inflation rate and nominal rate are slightly lower, as expectations of a shift to the low growth regime lead to a lower real rate and a slight decline in economic activity. This decline leads to an increase in the zero bound frequency 
to about 1\%. In the low regime, the opposite largely holds: expectations of a switch to the higher growth rate increase the inflation rate and nominal rate, and hence lower the zero bound frequency. The overall outcomes across regimes thus imply a slightly positive inflation rate, and a frequency of the zero bound over $5 \%$. The welfare loss of $2.6 \mathrm{bp}$ is small in absolute terms.

Turning to the optimal constant rule, the inability to switch the real rate used to set the neutral nominal rate, plus the constant inflation target and inertia, lead to inferior outcomes relative to the naive switching rule. The constant rule means that in the high growth regime monetary policy is too accommodative, producing higher inflation and a nominal rate that ends up higher in equilibrium. This higher rate leads to the zero bound never being hit. In the low growth regime, the relatively restrictive monetary policy leads to negative inflation and an equilibrium nominal rate that is lower, and the zero bound is hit with nearly a $20 \%$ frequency. Further, when at the zero lower bound in this regime, long-term rates are quite low, meaning that there is relatively little scope for unconventional policy to provide additional stimulus. The welfare loss from this case is nearly double the loss of the naive switching rule.

Lastly, the optimal switching rule has parameters that are slightly different from the naive switching rule. These parameter adjustments are intended to offset some of the spillover effects of regime switching that the naive rule does not take into account. Relative to the constant rule, the inflation and nominal rates are slightly higher in the high growth regime, and slightly lower in the low growth regime. The zero lower bound is then hit with slightly higher and lower frequency, respectively. Interestingly, these results imply that the naive rule leads to the zero lower bound being hit with a frequency that is too low relative to the optimal. In other words, while hitting the zero lower bound is costly, too high inflation is costly as well, meaning that it is possible that the bound is not hit frequently enough due to too high inflation. In the low growth regime, long-term rates indicate a higher ability to use unconventional policies as an additional form of stimulus. In sum, the optimal rule produces very minor gains over the naive rule.

It is interesting to note that the mean inflation rates in each regime shown in Table 3 differ from the stated inflation targets, even in the case when the inflation target switches. The monetary authority chooses the inflation target, but expectation effects yield average inflation rates that are either above or below target depending on the regime and rule. The switching generates spillovers across regimes that lead to expectations of either higher or lower inflation in the future, and these expectations lead to corresponding moves in contemporaneous inflation that lead it to differ from the target (Foerster, 2016). Similarly, expectations of being constrained by the zero lower bound and unable to provide additional accommodation through nominal rate 
decreases produces downward pressure on expected and hence current inflation (Hills et al., 2016). From the standpoint of an optimizing monetary authority, these misses are expected and internalized when setting policy.

These considerations produce an implication for the dynamics of inflation and the nominal rate across regimes. Specifically, while both optimal constant and optimal switching rules will have lower nominal rates in the low growth regime than the high growth regime, the implications for inflation differ. The constant rule produces lower inflation in the low growth regime, whereas the opposite is true for the switching and naive rule. It is notable that the the welfare preferred rules imply higher inflation when growth is low, whereas the welfare inferior rule implies lower inflation.

To summarize, the results in this section point to the need to consider cross-regime expectation effects when setting policy parameters. The trade-off between inertia and inflation targets is an important piece of setting optimal policy rules, as higher levels of inertia can substitute for high inflation targets. Further, there are welfare gains from having a rule that switches along with the regime, with the real rate being used in the neutral nominal rate being an important factor. A key assumption in this analysis, however, is that it relies on synchronized switching for the monetary policy rule and the growth regime. The next section consider the implications when the monetary policy may misidentify the regime and put the wrong rule into place.

\section{The Cost of Monetary Policy Errors}

The results in the previous section show that a switching rule can have welfare gains over a constant one, in particular by adjusting the real interest rate used to determine the neutral nominal rate. However, identifying regime changes in technology growth in real time may be difficult. In addition, a monetary authority may simply fail to implement the intended rule at the correct time. Both of these caveats cast doubt on the assumption that the monetary authority always switches its policy rule exactly in sync with changes in the growth rate. To address this issue, consider an environment where the economy switches between high and low growth regimes as before, but now the monetary authority correctly implements the relevant rule in place with probability $q$. They make a policy error with probability $1-q$, either putting the low growth rule into place during the high growth regime, or the high growth rule into place during the low growth regime. When $q=1$, the monetary policy authority never makes an error and the model collapses back to the version studied in the previous section.

The probability $q$ can be thought of as a shorthand for a learning process which allows for 
Figure 4: Monetary Policy Errors and Relative Welfare Loss

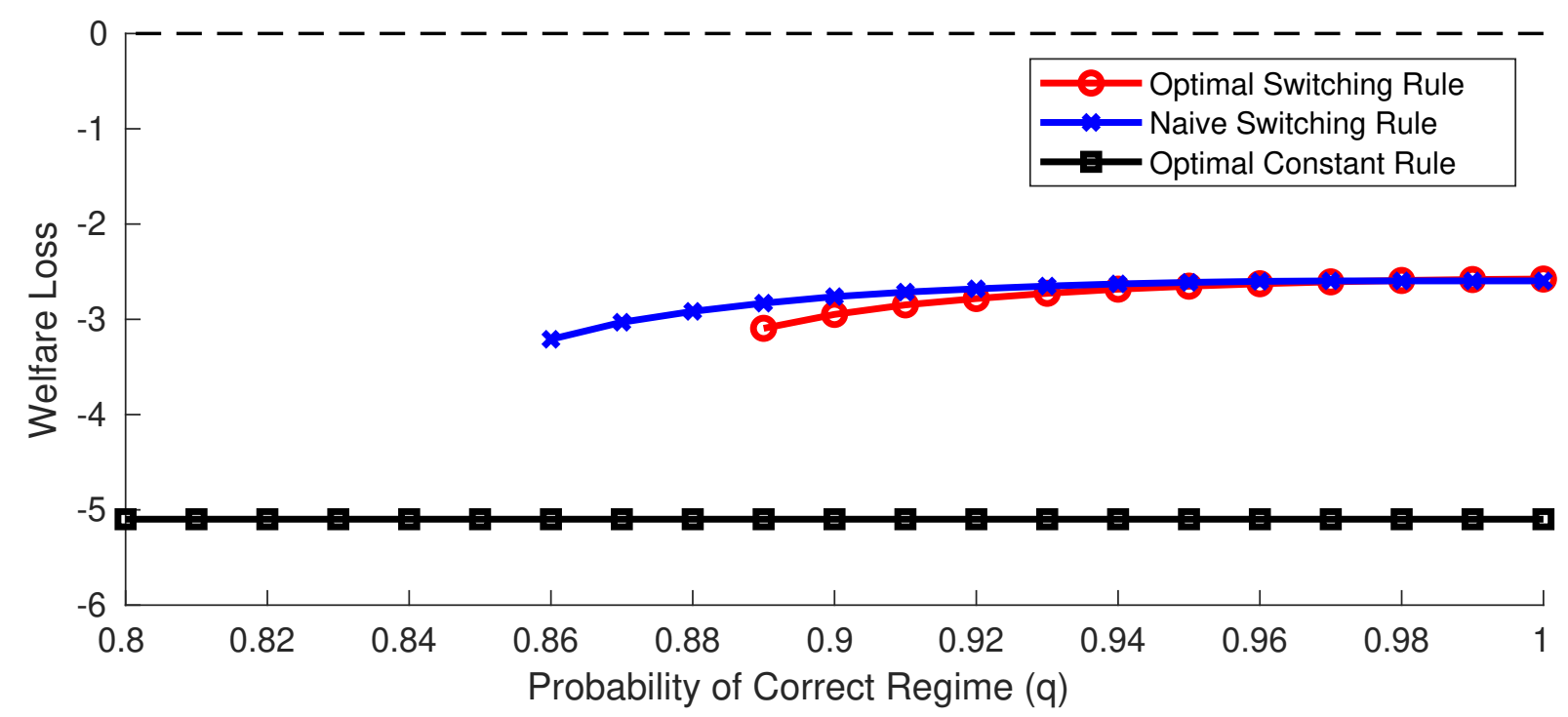

Note: Welfare loss is in basis points relative to the Ramsey steady state. Loss is plotted for values with a solution, other values produced no solution.

incorrectly realized rules in a framework close to the original specification that doesn't resort to requiring a filtering problem by the monetary authority. Alternatively, it can simply be interpreted as a measure of ability to successfully enact the intended rule. This motivation is related to Hachem and $\mathrm{Wu}$ (2017), who develop a framework where abrupt increases in the inflation target, such as that attempted in recent years by Japan, will fail to increase inflation as intended.

Figure 4 shows how the probability of correctly implementing the regime $q$ affects the welfare loss, relative to the Ramsey steady state, for the constant rule, the optimal switching rule, and the naive switching rule shown in Table 3. The constant rule has a welfare loss of 5.1bp, but is unaffected by the probability of errors, since it is unresponsive to regime switches. As noted above, the optimal switching achieves about a $50 \%$ lower welfare loss when $q=1$. As the probability of errors increases, the switching rule becomes slightly less beneficial. For values of $q$ of 0.88 or higher, the equilibrium exists and is welfare superior to the constant rule. However, the fragility of the equilibrium occurs quickly. When $q$ is 0.87 or lower, then the economy sinks into a deflationary spiral. This result is because the monetary authority does not stabilize inflation enough at the zero lower bound during the low growth regime when it implements the optimal high rule. Expectations for the insufficient stabilization lead to spillovers even away from the 
zero bound, and a deflationary spiral occurs. ${ }^{6}$ The naive switching rule follows a similar pattern, although due to the fact that it is not optimized when $q=1$, it actually shows slightly more robustness for maintaining an equilibrium as $q$ declines.

The results in Figure 4 therefore imply that the switching rule is slightly robust to errors. Even though it had been optimized in a model where no monetary policy errors were made, it provides some flexibility across regimes to be welfare-preferred relative to a constant rule. The switching rule that responds to changes in the real interest rate thus generates better outcomes than the constant rule, even taking into account that the monetary authority may make mistakes. Of course, if the probability of an error is high enough, the constant rule eliminates the issue of making errors and produces superior outcomes.

\section{Conclusion}

Motivated by recent arguments for changing the conduct of monetary policy in the presence of regime shifts in the growth rate of the economy, this paper has studied optimal monetary policy rules that switch parameters. These rules differ from the optimal choice under fixed regimes. Setting parameters in a way that considers the trade-off between inertia and the inflation target, as well as the expectation effects of regime switching, is an important aspect of monetary policy rules. A rule that switches whenever the growth rate regime switches outperforms a constant rule from a welfare standpoint. If the incidence of monetary policy rule errors is high enough, the constant rule can be welfare preferred.

The results in this paper therefore have several implications for the conduct of monetary policy when the economy experiences growth rate switches. First, setting a monetary policy rule should be done as a whole rather than focusing on a single aspect of that rule such as the inflation target. Second, monetary policy parameters set during times of high growth or low growth may not be optimal in the presence of regime switching; taking regime switches into account and the feedback effects from expectations is crucial in setting optimal rules. Finally, having a flexible rule that switches whenever the growth regime changes can yield superior macroeconomic outcomes from a constant rule if the incidence of errors is not too high.

\footnotetext{
${ }^{6}$ The fact that the optimal switching and naive switching rules welfare dominate the constant rule until they suddenly produce no solution highlights how quickly the deflationary spirals can set in to deviations in the policy environment (Bianchi et al., 2019).
} 


\section{References}

Ball, L. (2013). The Case for Four Percent Inflation. Central Bank Review 13(2), 17-31.

Bianchi, F. (2013). Regime Switches, Agents' Beliefs, and Post-World War II US Macroeconomic Dynamics. Review of Economic Studies 80(2), 463-490.

Bianchi, F., L. Melosi, and M. Rottner (2019). Hitting the Elusive Inflation Target. NBER Working Papers 26279, National Bureau of Economic Research, Inc.

Billi, R. M. (2011). Optimal Inflation for the US Economy. American Economic Journal: Macroeconomics 3(3), 29-52.

Blake, A. P. and F. Zampolli (2011). Optimal Policy in Markov-switching Rational Expectations Models. Journal of Economic Dynamics and Control 35(10), 1626-1651.

Blanchard, O., G. Dell'Ariccia, and P. Mauro (2010). Rethinking Macroeconomic Policy. Journal of Money, Credit, and Banking 42(s1), 199-215.

Blanco, A. (2018). Optimal Inflation Target in an Economy with Menu Costs and an Occasionally Binding Zero Lower Bound. Working Paper.

Coibion, O., Y. Gorodnichenko, and J. Wieland (2012). The Optimal Inflation Rate in New Keynesian Models: Should Central Banks Raise Their Inflation Targets in Light of the Zero Lower Bound? Review of Economic Studies 79(4), 1371-1406.

Coleman, Wilbur John, I. (1990). Solving the Stochastic Growth Model by Policy-Function Iteration. Journal of Business \&f Economic Statistics 8(1), 27-29.

Davig, T. (2016). Phillips Curve Instability and Optimal Monetary Policy. Journal of Money, Credit and Banking 48(1), 233-246.

Davig, T. and E. Leeper (2007). Generalizing the Taylor Principle. American Economic Review $97(3), 607-635$.

Debortoli, D. and R. Nunes (2014). Monetary Regime Switches and Central Bank Preferences. Journal of Money, Credit and Banking 46(8), 1591-1626.

Dordal-i-Carreras, M., O. Coibion, Y. Gorodnichenko, and J. Wieland (2016). Infrequent but Long-Lived Zero-Bound Episodes and the Optimal Rate of Inflation. Annual Review of Economics $8(1), 497-520$. 
Fernald, J. G. (2012). A Quarterly, Utilization-Adjusted Series on Total Factor Productivity. Working Paper Series 2012-19, Federal Reserve Bank of San Francisco.

Foerster, A. (2016). Monetary Policy Regime Switches and Macroeconomic Dynamics. International Economic Review 57(1), 211-230.

Foerster, A. and C. Matthes (2020). Learning about Regime Change. Working Paper Series 2020-15, Federal Reserve Bank of San Francisco.

Gertler, M. and P. Karadi (2013). QE 1 vs. 2 vs. 3. . . : A Framework for Analyzing Large-Scale Asset Purchases as a Monetary Policy Tool. International Journal of Central Banking 9(1), $5-53$.

Gordon, R. J. (2012). Is U.S. Economic Growth Over? Faltering Innovation Confronts the Six Headwinds. Working Paper 18315, National Bureau of Economic Research.

Greenwood, R. and D. Vayanos (2014). Bond Supply and Excess Bond Returns. Review of Financial Studies 27(3), 663-713.

Hachem, K. and J. C. Wu (2017). Inflation Announcements and Social Dynamics. Journal of Money, Credit and Banking 49(8), 1673-1713.

Hamilton, J. D. and J. C. Wu (2012). The Effectiveness of Alternative Monetary Policy Tools in a Zero Lower Bound Environment. Journal of Money, Credit and Banking 44, 3-46.

Hills, T. S., T. Nakata, and S. Schmidt (2016). The Risky Steady State and the Interest Rate Lower Bound. Finance and Economics Discussion Series 2016-9, Board of Governors of the Federal Reserve System (U.S.).

Liu, Z., D. Waggoner, and T. Zha (2009). Asymmetric Expectation Effects of Regime Shifts in Monetary Policy. Review of Economic Dynamics 12(2), 284-303.

Liu, Z., D. Waggoner, and T. Zha (2011). Sources of Macroeconomic Fluctuations: A RegimeSwitching DSGE Approach. Quantitative Economics 2(2), 251-301.

McKay, A., E. Nakamura, and J. Steinsson (2016). The Power of Forward Guidance Revisited. American Economic Review 106(10), 3133-3158.

Nakata, T. and S. Schmidt (2019). Gradualism and Liquidity Traps. Review of Economic Dynamics 31, 182-199. 
Nakov, A. (2008). Optimal and Simple Monetary Policy Rules with Zero Floor on the Nominal Interest Rate. International Journal of Central Banking 4(2), 73-127.

Negro, M. D., M. Giannoni, and C. Patterson (2012). The Forward Guidance Puzzle. Staff Reports 574, Federal Reserve Bank of New York.

Richter, A., N. Throckmorton, and T. Walker (2014). Accuracy, Speed and Robustness of Policy Function Iteration. Computational Economics 44(4), 445-476.

Rogoff, K. (2008). Inflation is Now the Lesser Evil. Project Syndicate. December 2.

Schmitt-Grohe, S. and M. Uribe (2007). Optimal Simple and Implementable Monetary and Fiscal Rules. Journal of Monetary Economics 54(6), 1702-1725.

Schmitt-Grohe, S. and M. Uribe (2010). The Optimal Rate of Inflation. In B. M. Friedman and M. Woodford (Eds.), Handbook of Monetary Economics, Volume 3 of Handbook of Monetary Economics, Chapter 13, pp. 653-722. Elsevier.

Schorfheide, F. (2005). Learning and Monetary Policy Shifts. Review of Economic Dynamics 8(2), 392-419.

Sims, E. R. and J. C. Wu (2019, July). Evaluating Central Banks' Tool Kit: Past, Present, and Future. NBER Working Papers 26040, National Bureau of Economic Research, Inc.

Summers, L. (2014). U.S. Economic Prospects: Secular Stagnation, Hysteresis, and the Zero Lower Bound. Business Economics 49(2), 65-73.

Woodford, M. (2003). Interest and Prices. Princeton: Princeton UP.

Wu, J. C. and F. D. Xia (2016). Measuring the Macroeconomic Impact of Monetary Policy at the Zero Lower Bound. Journal of Money, Credit and Banking 48(2-3), 253-291. 